\title{
CORRELAÇÃO ENTRE ESTADIAMENTO TNM E PARÂMETROS CLÍNICOS, PROGNÓSTICO E SOBREVIDA DOS PACIENTES PORTADORES DE CARCINOMA EPIDERMÓIDE ORAL DIAGNOSTICADOS NO CENTRO DE REFERÊNCIA DE LESÕES BUCAIS DA UEFS.
}

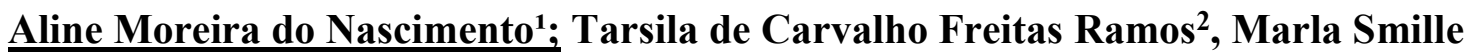 \\ Pedrosa Cruz Ribeiro ${ }^{3}$; Márcio Campos Oliveira ${ }^{4}$. \\ 1.Bolsista FAPESB, Graduanda em odontologia, Universidade Estadual de Feira de Santana, email: \\ alineemoreira94@gmail.com \\ 2.Orientador, Departamento de Saúde, Universidade Estadual de Feira de Santana, email: \\ tarsilafreitas@yahoo.com.br \\ 3.Pesquisadora do Núcleo de Câncer Oral, Departamento de Saúde, Universidade Estadual de Feira de \\ Santana, email:m.smille@hotmail.com \\ 4. Pesquisador do Núcleo de Câncer Oral, Universidade Estadual de Feira de Santana, email: \\ marciopatologiaoral@gmail.com
}

PALAVRAS-CHAVE: Carcinoma epidermóide oral; Prognóstico; Sistema TNM

\section{INTRODUÇÃO}

O carcinoma epidermóide oral é uma neoplasia maligna que se origina no epitélio de revestimento, sendo considerada a neoplasia maligna mais comum nesta região. As taxas de incidência e mortalidade para o carcinoma epidermóide oral variam de um país para outro e mesmo dentro de cada país. Essas variações ocorrem, principalmente, pelas diferenças de hábitos, características socioeconômicas, expectativa de vida, fatores ambientais, raça, educação preventiva e qualidade da assistência médica nas diversas regiões (BRENER et al., 2007). A distribuição das taxas de incidência e de mortalidade de tumores malignos, inclusive o carcinoma epidermóide oral, tem sido, em muitos países, de grande importância para o estabelecimento de diretrizes de políticas públicas em âmbito nacional, estadual e municipal e para o planejamento de ações de prevenção e controle do câncer, além de formas de tratamento ou assistência terapêutica (ARAÚJO et al., 1998). O prognóstico de pacientes com carcinoma epidermóide oral depende da área da cavidade oral comprometida e do estadiamento do sistema TNM (INCA, 2016). O sistema TNM tem sido utilizado como padrão internacional para classificar as neoplasias malignas em estádios e estimar tanto a resposta clínica à terapia quanto a sobrevida dos pacientes (SAWAIR et al., 2003; LOURENÇO et al., 2007; LINDENBLAT et al., 2012). Além de abranger detalhes das características anatômicas locais, esse sistema auxilia na obtenção de dados sobre o grau de envolvimento dessas estruturas pelo tumor, assim como metástases à distância, delineando o prognóstico e a sobrevida do paciente (COSTA et al., 2005). Atualmente, o diagnóstico e o tratamento são baseados nas características clínicas e histopatológicas.

Este trabalho tem como objetivo mostrar a relação entre a classificação do sistema TNM com parâmetros clínicos do tumor, prognóstico e tratamento de pacientes portadores de carcinoma epidermóide oral diagnosticados no Centro de Referência em Lesões Bucais da Universidade Estadual de Feira de Santana e tratados na Unidade de Alta Complexidade em Oncologia (UNACON) do Hospital Dom Pedro de Alcântara em Feira de Santana-BA.

\section{METODOLOGIA}

Foi realizado um estudo retrospectivo incluindo a revisão de prontuários clínicos odontológicos da Disciplina Estudos Integrados XIV da UEFS e prontuários médicos da UNACON, visando à busca de informações clínicas sobre os pacientes afetados pelo carcinoma epidermóide oral, além de informações sobre o Estadiamento Clínico (Sistema TNM), prognóstico, sobrevida e tratamento realizado. Os resultados obtidos foram 
submetidos às análises estatísticas com testes do Qui-Quadrado e Teste exato de Fisher. O estudo foi realizado observando a Resolução 466/12 (Cap. IX.2) que diz respeito à pesquisa envolvendo seres humanos (BRASIL, 2012). Os prontuários dos pacientes investigados continham o TCLE, onde era esclarecido que todas as informações contidas nos mesmos poderiam ser utilizadas em pesquisas e divulgações científicas. Vale ressaltar que este estudo se encontra registrado no Comitê de Ética da Universidade Estadual de Feira de Santana (CEP-UEFS) sob protocolo, No 015/2008, CAAE 0015.0.059.000-08.

\section{RESULTADOS E DISCUSSÃO}

Foram selecionados 50 prontuários baseados nos critérios de inclusão e exclusão desta pesquisa. A maioria dos pacientes eram do gênero masculino representando $72 \%$ da amostra $(n=32)$ e 43,5\% eram faiodermas. Em relação ao estado civil, 40,8\% eram casados. (Tabela 1). A ocupação mais citada foi lavrador $(36,2 \%)$, os aposentados (inativos) representaram 19,1\%. Evoluíram para óbito $56,7 \%$ dos pacientes. A média de idade dos pacientes acometidos foi de 60 anos, com desvio-padrão de 12 anos. Em relação aos aspectos histológicos, $60 \%(\mathrm{n}=24)$ eram moderadamente diferenciados.

As informações da Tabela 2 evidenciaram que houve associação estatisticamente significante $(p=0,041)$ com relação ao consumo de álcool e tabaco e estadiamento. Dos pacientes afetados, 70,8\% $(\mathrm{n}=34)$ relataram hábito tabagista e ingestão de bebidas alcoólicas. Constatou-se uma relação estatisticamente significante entre as variáveis tratamento e estadiamento $(\mathrm{p}<0,001)$, onde 11 pacientes $(78,6 \%)$ foram estadiados em Graus I e II, sendo os mesmos submetidos à cirurgia como modalidade terapêutica exclusiva, já os pacientes estadiados em Graus III e IV, representados por 21 pacientes $(100 \%)$ desta amostra, foram submetidos à terapia conjugada com quimioterapia e radioterapia (Tabela 3). Os locais mais acometidos pela doença foram o assoalho de boca com 15 casos $(30 \%)$ e a língua com 14 casos $(28 \%)$, seguidos do lábio $(14 \%)$ e palato (12\%). Também foi estatisticamente significante a associação desta variável com estadiamento $(\mathrm{p}=0,003)$, como mostra a tabela 4 .

De forma geral, observou-se semelhança entre as características observadas e aquelas descritas por outros autores: maioria do sexo masculino, entre a $5^{\mathrm{a}}$ e $6^{\mathrm{a}}$ década de vida, localizações mais frequentes para língua e assoalho bucal, além de diagnóstico em estádios tardios para a maior parte dos pacientes investigados. Com relação aos hábitos carcinogênicos mais fortemente associados, permitiu-nos atribuir ao tabaco e álcool elevado risco no desenvolvimento do câncer de boca, conforme já mencionado na literatura descrita por Deusdedit et al (2016). Além disso, o sinergismo entre tabaco e álcool eleva a probabilidade para o surgimento do câncer bucal. Em estudo realizado por Costa et al (2005) a maioria dos pacientes pertenciam aos estádios clínicos III e IV. Na casuística aqui apresentada, observa-se a manutenção desta tendência. Tal característica aponta para a manutenção e talvez agravamento no diagnóstico tardio dessa doença no Brasil. 
Tabela 1. Características sociodemográficas dos pacientes com diagnóstico de carcinoma escamocelular, CRLB/NUCAO, Feira de Santana, Bahia 2017.

\begin{tabular}{r|cc} 
CARACTERÍSTICAS & $N$ & $\%$ \\
Gênero & 36 & 72 \\
Masculino & 14 & 28 \\
Feminino & & 43,5 \\
Cor da pele* & 20 & 26,1 \\
Faioderma & 12 & 26,1 \\
Leucoderma & 12 & 4,3 \\
Melanoderma & 2 & \\
Xantoderma & & 40,8 \\
Estado civil* & 20 & 32,7 \\
Casado & 16 & 14,3 \\
Solteiro & 7 & 12,2 \\
Viúvo & 6 & \\
Divorciado & & \\
*1 paciente não informado & &
\end{tabular}

Tabela 2. Associação entre Consumo de álcool e tabaco e Estadiamento em indivíduos com carcinoma escamocelular, CRLB/NUCAO, Feira de Santana Bahia, 2017.

\begin{tabular}{l|cccccc}
\hline Consumo de álcool e tabaco & \multicolumn{5}{c}{ Estadiamento } \\
& Graus III e IV & $\%$ & Graus I e II & $\%$ & $\mathrm{p}^{*}$ \\
\hline Apenas álcool & 1 & 25 & 3 & 75 & \\
Apenas tabaco & 1 & 25 & 3 & 75 & 0,041 \\
Álcool e tabaco & 25 & 78,1 & 7 & 21,9 & \\
Nenhum dos dois & 3 & 60 & 2 & 5 & \\
$*$ Teste Exato de Fisher &
\end{tabular}

Tabela 3. Associação entre Tipo de tratamento e estadiamento em individuos com carcinoma escamocuelar, UNACOM, Feira de Santana Bahia, 2017.

\begin{tabular}{l|ccccc}
\hline Tipo de tratamento & \multicolumn{5}{c}{ Estadiamento } \\
& Graus III e IV & $\%$ & Graus I e II & $\%$ & $\mathrm{p}^{*}$ \\
\hline Cirurgia & 3 & 21,4 & 11 & 78,6 & \\
Cirurgia e adjuvantes & 7 & 77,8 & 2 & 22,2 & 0,000 \\
Radioterapia e/ou & 21 & 100 & 0 & 0 & \\
quimioterapia & & & & & \\
*Teste Exato de Fisher &
\end{tabular}


Tabela 4. Associação entre Localização da lesão e estadiamento em individuos com carcinoma escamocuelar, CRLB/NUCAO, Feira de Santana Bahia, 2017.

\begin{tabular}{l|ccccc}
\hline Localização da lesão & \multicolumn{5}{|c}{ Estadiamento } \\
& Graus III e IV & $\%$ & Graus I e II & $\%$ & $\mathrm{p}^{*}$ \\
\hline Assoalho bucal & 10 & 76,9 & 3 & 23,1 & \\
Língua & 11 & 78,6 & 3 & 21,4 & \\
Lábio & 0 & 0 & 7 & 100 & \\
Palato & 5 & 83,3 & 1 & 16,7 & 0,003 \\
Rebordo & 4 & 100 & 0 & 0 & \\
Mucosa jugal & 0 & 0 & 1 & 100 & \\
Orofaringe & 1 & 100 & 0 & 0 & \\
Seio Maxilar & 1 & 100 & 0 & 0 & \\
\hline
\end{tabular}

*Teste Exato de Fisher

\section{CONCLUSÃO}

Os resultados deste estudo estão de acordo com a literatura no que tange à idade dos pacientes afetados, localização anatômica, estadiamento clínico e graduação histológica dos tumores, além disso, este estudo reforça a necessidade de se estabelecer políticas públicas de combate ao câncer bucal, enfatizando, principalmente, a importância da prevenção e do diagnóstico precoce uma vez que a maioria dos pacientes encontrados nesta amostra apresentavam a doença em estágio avançado requerendo tratamentos mais complexos.

\section{REFERÊNCIAS}

ARAÚJO FILHO, V.J.F.; DE CARLUCCI, J.D.; SASAKI SU. Perfil da incidência do câncer oral em um hospital geral em São Paulo. Rev Hosp Clin Fac Med São Paulo. 1998;55(3):11013.

BRENER, S.; JEUNON, F.A.; BARBOSA, A.A.; GRANDINETTI, H.A.M. Carcinoma de células escamosas bucal: uma revisão de literatura entre o perfil do paciente, estadiamento clínico e tratamento proposto. Revista Brasileira de Cancerologia 2007; 53(1): 63-69 COSTA, A.L.L., JÚNIOR, R.F.A., RAMOS, C.C.F. 2005. Correlação entre a classificação clínica TNM e as características histológicas de malignidade do carcinoma epidermóide oral. Rev. Brasileira de Otorrinolaringologia. V.71, n.2, p 181-7.

DEUSDEDIT, M.B., TELLES, P.J., CRUZ, A.F., LACERDA, J.C.T., RESENDE, R.G. 2016. Análise da prevalência de carcinoma de células escamosas da cavidade bucal no Serviço de Estomatologia do Hospital Metropolitano Odilon Behrens em Belo Horizonte, Minas Gerais. Arq Odontol, Belo Horizonte, 52(4): 182-187.

LINDENBLATT, R.C.R. et. al. Oral Squamous cell carcinoma grading systems - analysis of the best survival predictor. J Oral Pathol Med, v.41, p. 34-9, 2012. LOURENÇO, S.Q.C. et al. Classificações histopatológicas para o carcinoma de células escamosas da cavidade oral:

Revisão de sistemas propostos. Rev Bras de Canc, v.53, n.3, p. 325-33, 2007.

NEVILLE, B.W.; DAMM, D.D.; ALLEN, C.M.; BOUQUOT, J.E. Patologia Oral e Maxilofacial. Trad.3a Ed., Rio de Janeiro: Elsevier, 2009, 972p.

SAWAIR, F. A. et al. Invasive front grading: reliability and usefulness in the management of oral squamous cell carcinoma. J Oral Pathol Med. v.32, n.1, p. 1-9, 2003. 